\title{
PULSING A 4.1 MW MOTOR GENERATOR SYSTEM TO 34 MW PEAK POWER UNDER CONSTANT INPUT POWER OPERATION. *
}

\author{
I. Marneris \#, V. Badea, M. Bannon, R. Bonati, G. Danowski, J. Sandberg, A. Soukas. \\ Brookhaven National Laboratory, Upton, New York 11973 USA
}

\section{Abstract}

Brookhaven operates a $9 \mathrm{MW}$ motor generator, made by Siemens, as part of the main magnet power supply of the Alternating Gradient Synchrotron (AGS) accelerator. A cycloconverter power supply system is utilized to ensure that during pulsing the main magnets of the AGS up to $50 \mathrm{MW}$ peak power, the input power of the motor generator remains constant. There is also another motor generator (MG set) at Brookkhaven, a 40 year old system manufactured by Westinghouse. This MG set could be pulsed up to $34 \mathrm{MW}$ peak power while the input average power should not exceed. 4.1 MW. A project is underway to upgrade this MG system and it's controls, so it could be used as a spare while doing maintenance on the Siemens MG and thus not interrupting the RHIC physics program. The purpose of this paper is to show that it is possible to pulse the AGS magnets using the Westinghouse MG system without utilizing a cycloconverter power supply, and still be able to maintain the input power to the motor generator constant. Calculations will be provided to show that we can pulse the position of the liquid rheostat in the motor rotor circuit to support the above, while taking out the power necessary to pulse the AGS magnets. This solution is being implemented due to budget constraints and overall simplicity. The hydraulic system to accomplish this task will also be described.

\section{DESCRIPTION/SPECIFICATIONS OF THE MOTOR/GENERATOR}

The motor generator is a 40 years old machine manufactured by Westinghouse (WH) with the following ratings. The stator voltage is Vst $=13800$ Volts 3 phase, stator full-load current is 203 Amps. The motor is an $900 \mathrm{RPM}, 6 \%$ slip, 5500 horsepower (4.1 MW) wound rotor induction motor. The friction and windage losses are $550 \mathrm{KW}$. The blocked rotor voltage is 3168 Volts, rotor full-load current is 787 Amps. The moment of inertia of the whole system is $46890 \mathrm{~kg}^{*} \mathrm{~m}^{*} \mathrm{~m}$. A liquid rheostat is used for acceleration and speed adjustments. The liquid rheostat consists of the coarse adjustment used curing turning on and braking the motor and the fine adjustment used to control the speed during pulsing of the generator. The generator stator voltage generates a maximum of 7500 volts, 3 phase, 2771 Amps, 36000
KVA. It can be pulsed up to $34200 \mathrm{KW}$, with a power factor of $95 \%$. The continuous rating is $29 \mathrm{MW}$. The generator rotor is excited by a dc source of 260 Volts at 578 Amps. The 3 phase output is converted to controllable dc by a rectifier (SCR) system and applied to the AGS magnets.

\section{THEORY AND CALCULATIONS}

Since we can pulse the WH generator to $34 \mathrm{MW}$ peak power and assuming a linear change of the magnet current from the front porch to the flat top value and visa versa, we can calculate the optimum magnet current waveform based on the $34 \mathrm{MW}$ peak power rating assuming an efficiency of $95 \%$ for the rectifiers. The magnet current $I(t)$, magnet voltage $V(t)$ and magnet instantaneous power $\operatorname{Pim}(\mathrm{t})=\mathrm{I}(\mathrm{t}) * \mathrm{~V}(\mathrm{t})$ are displayed in Fig. 1 and Fig 2, for a typical AGS cycle.

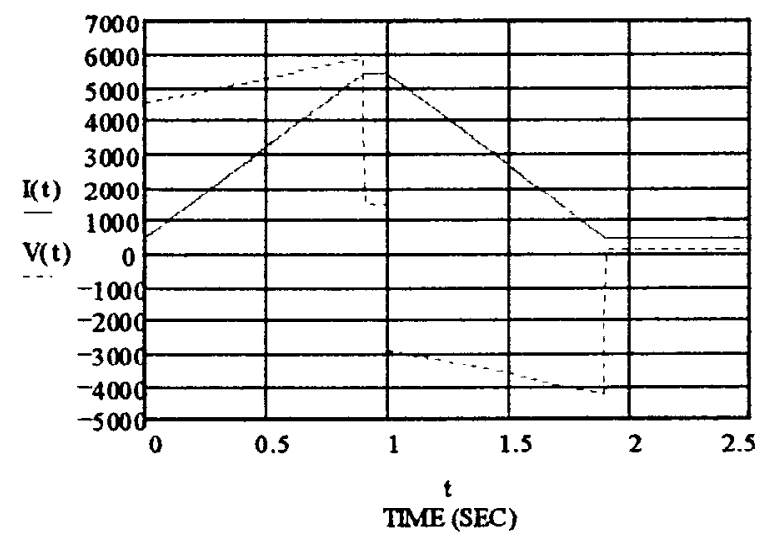

Figure 1: Magnet current (Amps) and voltage (Volts)

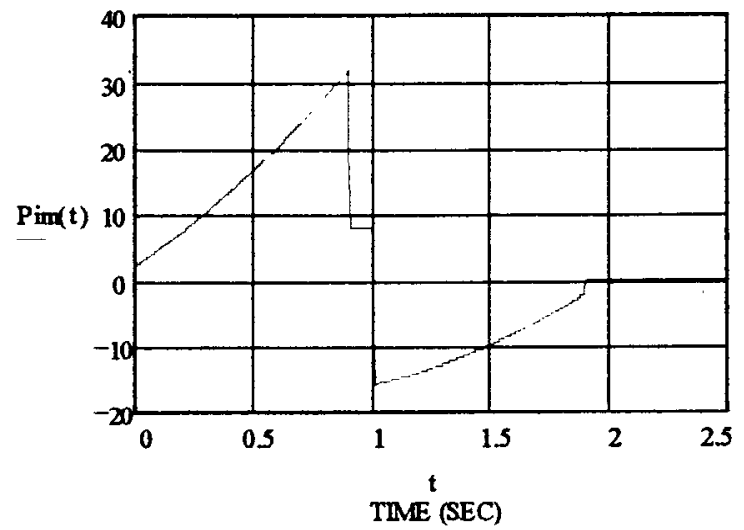

Figure 2: Magnet power (Mwatts) 
NOTE $\operatorname{Pim}(t)=I(t) *(L * d / / d t+I(t) * R)$

$\mathrm{R}=0.27 \mathrm{Ohms}$ is the AGS magnet total resistance. $\mathrm{L}=0.75$ Henry is the inductance of the AGS magnets.

The differential equation governing the motor generator power flow is:

$P(t)=J \cdot \Omega(t) \cdot \frac{d^{1}}{d t^{1}} \Omega(t)+P w+P i m(t)+\operatorname{Pscr}(t)+\operatorname{Plose}(t)$

$\mathrm{Pi}(\mathrm{t})$ is the input power into the motor as function of time. $J$ is the moment of inertia. $\Omega(t)$ is the rotational speed of the MG set in $\mathrm{rad} / \mathrm{sec}$. $P w=550000 \mathrm{~W}$, is the friction and windage loss. Pim(t) is the instantaneous AGS magnet power. Pscr(t) is the power dissipated on the silicon control rectifiers for the AGSMMPS. Plose(t) represents all other loses measured for a given magnet cycle used in this example. $\mathrm{T}=2.5 \mathrm{sec}$, is the period of the AGS magnet cycle. $P i$, the average power into the MG set, is equal to the sum of the average power Pam dissipated into the AGS magnets, plus the average power dissipated on the SCR's Pscr, plus the windage loss Pw, plus the all other average losses Plose, for a given magnet cycle. Rlose was measured to be $0.073 \mathrm{Ohms}$.

$\mathbf{P i}:=\mathbf{P a m}+\mathbf{P w}+\mathbf{P s c r}+\mathbf{P l o s e}$

Pam $:=\frac{R}{T} \cdot \int_{0}^{T} I(t)^{2} d t \quad$ Plose $:=\frac{\text { Rlose }}{T} \cdot \int_{0}^{T} I(t)^{2} d t$

Pscr $:=\frac{1}{T} \cdot \int_{0}^{T} I(t) \cdot 32 d t$

$P=\frac{R+R \text { lose }}{T} \cdot\left(\int_{0}^{T} I(t)^{2} d t\right)+\frac{32}{T} \cdot\left(\int_{0}^{T} I(t) d t\right)+P w$

Pi was calculated to be $3.7 \mathrm{MW}$ for the magnet cycle in Fig. 1. Utilizing Mathcad 5.0 software we solved the differential equation governing the MG set for the rotational speed $\Omega(t)$. This is the speed, that the MG set should have for the magnet current in Fig. 1, maintaining the input power $P i=3.7 \mathrm{MW}$ constant. $\Omega 0=93.2 \mathrm{rad} / \mathrm{sec}$ is the speed of the MG set without a load on the generator. $\Omega e=94.2 \mathrm{rad} / \mathrm{sec}$ is the synchronous speed of the stator magnetic field wich induces EMF on the rotor windings. The result is,

$$
\Omega(t)=\sqrt{\Omega 0^{2}+\frac{2}{J} \cdot(P i \cdot t-P w \cdot t-a(t)-b(t)-c(t)-d(t))}
$$

Where

$$
\begin{aligned}
& a(t):=L \cdot \int_{I(0)}^{I(t)} \quad I d I \quad b(t)=R \cdot \int_{0}^{t} I(t)^{2} d t \\
& c(t):=\int_{0}^{t} \operatorname{Pscr}(t) d t \quad d(t):=R \operatorname{lose} \cdot \int_{0}^{t} I(t)^{2} d t
\end{aligned}
$$

$S(t)$ is the slip of the MG set defined as,

$$
S(t):=\frac{\Omega e-\Omega(t)}{\Omega e} .
$$

Fig. 3 is the slip in percent for the magnet current cycle in Fig. 1 while maintaining the motor power Pi constant at $3.7 \mathrm{MW}$.

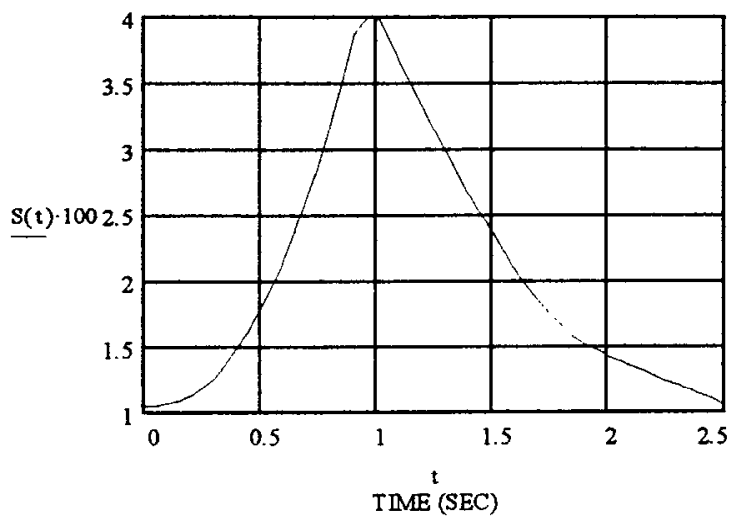

Figure 3: Slip of the MG set in percent

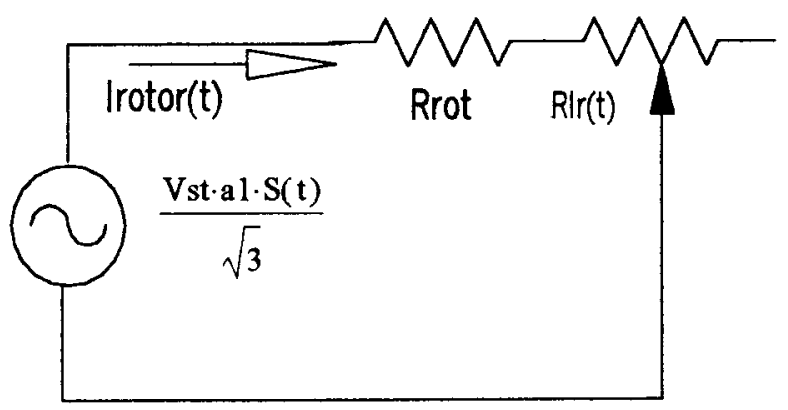

Figure 4: Induction motor rotor equivalent circuit per phase

From induction motor theory we have:

$$
\mathrm{al}=\frac{3168}{13800} \quad \frac{\operatorname{Vrotor}(t)}{\operatorname{Vstator}(t)}=\mathrm{al}_{\mathrm{al}} \cdot \mathrm{S}(\mathrm{t}) \quad \operatorname{Irotor}(\mathrm{t}) \quad \mathrm{I}=\frac{1}{\text { Istator }(t)}
$$

From the per phase equivalent circuit of the rotor of an induction motor, Fig. 4, assuming the rotor reactance to be 0 we have:

$$
\operatorname{Rtot}(t)=\operatorname{Rrot}+\operatorname{Rl}(t)
$$

Substituting for Irotor( $(t)$ we

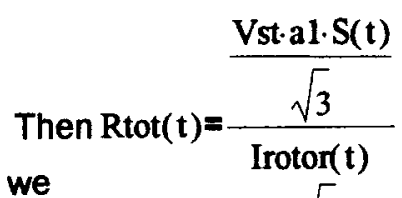

Since Istator $(t)=\frac{P i}{\sqrt{3} \cdot \text { Vst } \cdot P F(P i)}$

$$
\underset{P i}{\operatorname{Rtot}(t)}=V \operatorname{Vst}^{-a 1^{2}} \cdot \mathrm{S}(\mathrm{t}) \cdot \frac{\sqrt{3}}{\text { Istator }(t)}
$$

We finally have $\quad R$ tot $(t)=V s t^{2} \cdot a 1^{2} \cdot \frac{S(t)}{P i} \cdot P F(P i)$ 
From this formula we conclude that to maintain the power into the motor Pi constant, the resistance of the liquid rheostat $R \operatorname{lr}(t)$ should be proportional to the required or desired slip $S(t)$. We measured the power factor versus input power PF(Pi), into the MG and the data are displayed in Fig. 5. Fig. 6 displays the calculated resistance of the liquid rheostat, while pulsing the generator to approximately $34 \mathrm{MW}$ peak power and maintaining the input power to the motor constant at 3.7 MW.

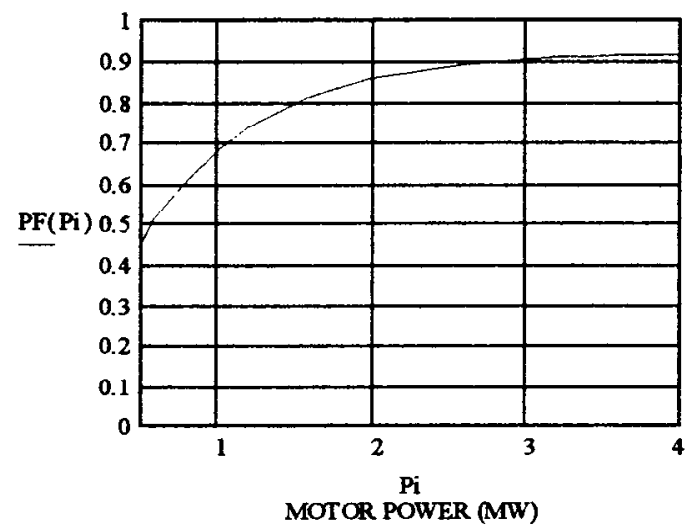

Figure 5: MG set power factor

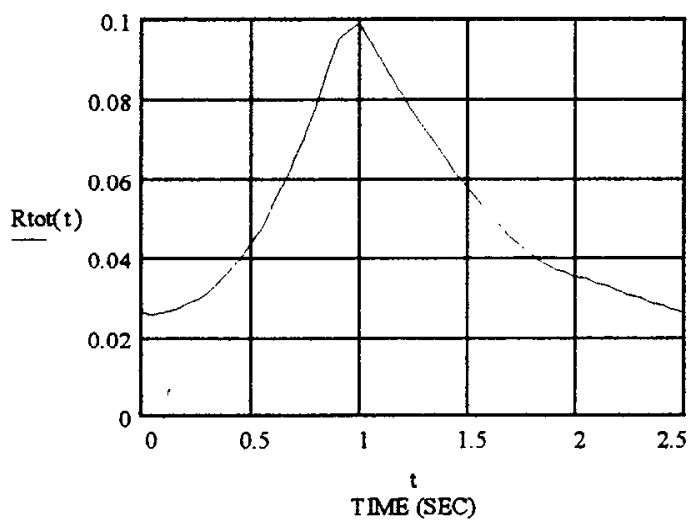

Figure 6: Motor rotor plus liquid rheostat resistance per phase in ohms

Since the resistance of the liquid rheostat is proportional to it's position, if we would pulse the position of the rheostat based on the above calculation subtracting the actual rotor resistance Rrot, which was measured to be 15 mOhm, the input power into the motor should be constant. The actual input power should be constant to $+/-0.5 \mathrm{MW}$.

\section{HYDRAULIC SYSTEM}

For pulsing operation of the MG set, a hydraulic system is used. The system consists of a pair of hydraulic pistons capable of moving the liquid rheostat fine adjustment by a maximum of 20 percent of the total liquid rheostat resistance. This corresponds to a maximum fine adjustment of $500 \mathrm{mOms}$. A 1000 psi pump is used with an electronically controlled Moog valve, to move the position of the fine adjustment. Three different techniques that could be utilized to regulate the motor power, are shown in the block diagram of Fig. 7. When the switch is in position A, a computer generated reference, for a given magnet cycle, will be utilized based on the formula for rotor resistance, calculated above, to drive the Moog valve. If the switch is in position $B$, the Moog valve will be driven by a computer generated reference based on the formula for the slip. This solution utilizes a feedback loop with reference the slip signal $S(t) * 100$ from Fig. 3, feedback signal the actual slip of the motor in percent, and the error signal driving the position of the fine adjustment of the liquid rheostat. If we choose position $\mathrm{C}$ of the switch, then the Moog valve will be driven by a computer generated reference based on the formula for motor power Pi. This solution utilizes a power requlation feedback loop where the error signal drives the position of the fine adjustment of the liquid rheostat, to maintain the input power constant. Sample speed could be used to adjust the power reference.

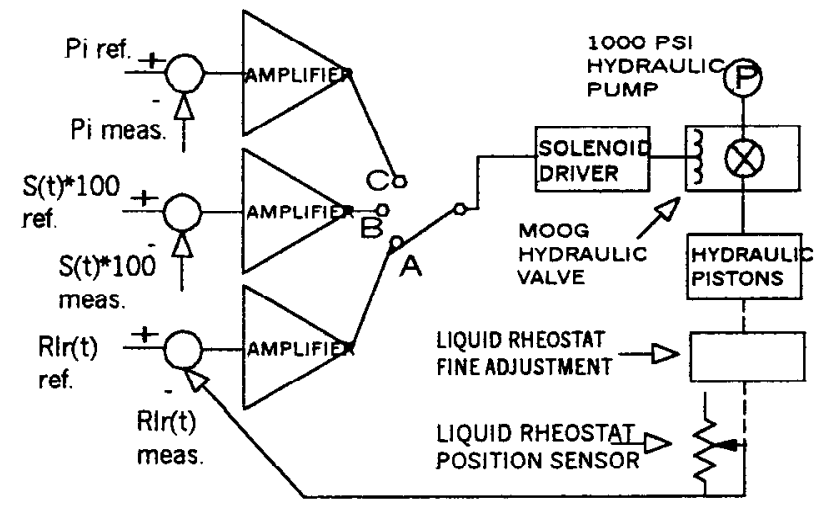

Figure 7: Liquid rheostat hydraulic system block diagram

\section{ACKNOWLEDGMENTS}

The authors wish to thank M. Meth, J. Spinner, W. Eng, P. Rosas, J. Morris and N. Schumburg, for their engineering support. We also thank S. Savatteri, J. Funaro, J. Lombardo, J. Jimenez, M. Hamilton, W Shaffer and V. Maltese for their technical support of this project.

\section{REFERENCES}

[1] Power Controller for AGS Main Magne Powrer Supply AGS/AD/Tech. Note No. 396, by M. Meth, J. Sandberg and J. Spimer, June 6, 1994.

[2] Electric Machinery Vol. II AC Machines Liwschitz-Garik and Whiple

- Worked performed under the auspices of the U.S.D.O.E.

\# Email: mameris@bnl.gov 